Article

\title{
Suitability and Profitability of a Cereal Aphid for the Parasitoid Aphidius platensis in the Context of Conservation Biological Control of Myzus persicae in Orchards
}

\author{
Jeniffer K. Alvarez-Baca ${ }^{1,2} \mathbb{D}$, Armando Alfaro-Tapia ${ }^{1,2}$, Blas Lavandero ${ }^{1, * \mathbb{D}}$, Cécile Le Lann ${ }^{2}$ \\ and Joan Van Baaren ${ }^{2}$ \\ 1 Laboratorio de Control Biológico, Instituto de Ciencias Biológicas, Universidad de Talca, \\ Talca 3460000, Chile; jealvarez@utalca.cl (J.K.A.-B.); aalfaro@utalca.cl (A.A.-T.) \\ 2 UMR 6553 Ecobio, Centre National de la Recherche Scientifique, Université de Rennes 1, \\ 263 Avenue du Général Leclerc, 35042 Rennes, France; cecile.lelann@univ-rennes1.fr (C.L.L.); \\ joan.van-baaren@univ-rennes1.fr (J.V.B.) \\ * Correspondence: blavandero@utalca.cl; Tel.: +56-71-2200271
}

Received: 14 May 2020; Accepted: 17 June 2020; Published: 19 June 2020

\begin{abstract}
The use of cover crops can promote the abundance and early arrival of populations of natural enemies. Cereal cover crops between orchards rows could encourage the early arrival of the parasitoid Aphidius platensis, as they offer alternative winter hosts (e.g., Rhopalosiphum padi), enhancing the control of Myzus persicae in spring. However, the preference for and suitability of the alternative host must be addressed beforehand. To evaluate the potential of this strategy, we assessed host preference using behavioural choice tests, as well as no-choice tests measuring fitness traits, when developing on both host species. One source field for each aphid population from the above hosts was chosen. There was a clear choice for $R$. padi compared to $M$ persicae, independently of the source, probably due to more defensive behaviours of $M$. persicae (i.e., kicks and escapes). Nevertheless, both aphid species were suitable for parasitoids' development. The female progeny developed on R. padi were larger in size, irrespective of their origin. According to our results, in peach orchards with cereals sown between peach trees during the autumn, where we expect when $R$. padi populations will no longer be available during spring, A. platensis should be able to switch to M. persicae.
\end{abstract}

Keywords: biological control; parasitoids; host selection; profitability; fitness

\section{Introduction}

Cover crops can be used as a habitat management strategy to enhance natural enemies' populations of a target pest, favoring natural enemies by means of different mechanisms. The mechanisms behind this proposed strategy, include providing shelter, from deleterious environmental factors such as pesticides, harvest, extreme weather and cultivation, among others, as well as providing host (other suitable species) and non-host resources such as nectar, pollen and honeydew [1-6].The use of this strategy has been increasing in recent years, in Europe [7,8] America [9,10], Asia and Africa [11-15] and Latin America [16]. Additionally, cover crops can provide conditions for the temporal synchronization of natural enemies and the target pest by means of the aforementioned mechanism, increasing natural enemy populations before pest arrival on the target crop [17-20]. This habitat management strategy has been shown to increase crop yields $[6,20,21]$ use of a mixture of cereal cover crops (Festuca arundinacea (Schreb), Poa sp.(Linnaeus), Bromus sp.(Linnaeus), etc.) in citrus orchards in Spain has been used to control the main aphid pest, Aphis spiraecola (Patch) (Hemiptera: Aphididae), and has been shown to 
significantly advance the arrival of predators [22] Similarly, in a study in New Zealand, the use of cover plants like alyssum (Lobularia maritima (Linnaeus)), buckwheat (Fagopyrum esculentum (Moench)) and phacelia (Phacelia tanacetifolia (Benth)) in apple orchards, increased the parasitism rates of the larvae of the light-brown apple moth, Epiphyas postvittana (Walker) (Lepidoptera: Tortricidae) in alyssum and buckwheat treatments compared to controls [23]. Prior to their establishment, an important aspect of cover crops to take into account is that they do not enhance the target pest [22]. Alternative hosts/prey must impact life history traits and development of the natural enemy species positively, but not affect their oviposition/feeding preference in relation to the target pest species [24]. Therefore, in order to correctly implement such a strategy, the alternative hosts/prey for the target natural enemies must be viable from a preference and a performance perspective.

Regarding host quality, different theories can explain the choices of a female parasitoid for oviposition. The optimal foraging theory predicts that a foraging female parasitoid will always prefer the most profitable host [25]. This is in relation to the preference-performance hypothesis (PPH), also known as the "mother knows best" hypothesis [26], which states that host preference in female parasitoids is positively correlated to the developmental success of its progeny [27-31]. However, in some cases, female inexperience or defensive behaviours of the host which can decrease its profitability by increasing the handling time [32] for example, it can lead to choices that can seem suboptimal [33]. It is also known that specialist parasitoids are more efficient at exploiting a host than generalist ones [34]. Parasitoids which are particularly locally adapted, can exhibit a higher performance and preference in relation to their target host, being more efficient $[35,36]$. The lower efficiency of generalist parasitoids can be avoided by host fidelity, which is traduced into preferentially attacking the same host species as those from which they emerged (i.e., natal hosts) [37]. Host fidelity allows a quicker recognition of the host, maximizing the reproductive success and survival of the progeny [38,39]. As the host fidelity of female parasitoids could result in more parasitoids remaining on their natal host and less host shift to alternative hosts [40], it is extremely important to be aware of this information in advance.

In Chile, 169 aphid species have been reported, with more than 100 of them having been introduced $[41,42]$. Most of these species constitute important agricultural pests in cereals, legumes and fruit orchards [43-46]. An economically important agricultural pest is the peach-potato aphid, Myzus persicae (Sulzer) ( Hemiptera, Aphididae), which frequently exhibits resistance to insecticides on several crops, including their primary host, the peach, Prunus persica (Linnaeus) $[43,47,48]$. On the other hand, Rhopalosiphum padi (Linnaeus) (Hemiptera, Aphididae) is an important insect pest attacking several host plants of wild and graminaceous crops, including wheat, oat and barley [47]. The polyphagous endoparasitoid Aphidius platensis Brethes (Hymenoptera, Braconidae) attacks several aphid species, and it is known to parasitize aphids that feed on different plant species, namely cultivated grasses, vegetables and fruit trees, including hosts of economic importance such as M. persicae and R. padi $[49,50]$. A recent survey in cereal fields during winter showed that $R$. padi's most abundant parasitoid is A. platensis, which represents $70 \%$ of the parasitoids emerging from the mummies (Alfaro-Tapia et al., unpublished data). It has been suggested that the populations of $R$. padi abandon cereal crops in early spring [51], forcing $A$. platensis to search for other host species. On the other hand, M. persicae populations increase on several Prunus species in early spring, and A. platensis has been collected and observed parasitizing M. persicae and Brachycaudus helichrysi Kaltenbac and Aphis spiraecola Patch (Hemiptera, Aphididae) on Prunus spp. orchards (Alvarez-Baca et al., unpublished).

In order to verify whether the parasitoid A. platensis effectively has the ability to switch from an alternative winter host $R$. padi to a spring target host $M$. persicae, we studied the preference and performance of $A$. platensis on the two aphid-plant complex species in the laboratory. We hypothesized that: (i) in a choice situation, the origin of the host of the parasitoid will not influence its choice: e.g., A. platensis females will show no host fidelity, as they are adaptive in order to be able to change hosts according to their relative availability during the season (ii) in a non-choice situation, both aphids will be suitable hosts in terms of survival and development for A. platensis, as parasitoid populations were 
collected and reared on both hosts. Therefore, M. persicae can be accepted by the female parasitoids independently of their origin.

\section{Materials and Methods}

\subsection{Insect Rearing}

\subsubsection{Parasitoids}

Aphidius platensis is a species belonging to the Aphidius colemani group [52]. It was initially believed to originate from South America (classified as a member of the Neotropical Faunistic Complex) [53], however, a few years later, it was documented as being of Indian origin [50], with a consequent expansion to other continents, currently being present in North Africa, Australia, Middle East and South America [54]. In this present study, two A. platensis populations were established for laboratory rearing. One parasitoid population came from $R$. padi mummies (i.e., parasitized aphids), collected during the winter season (July-August) on winter cereals (Talca, $35^{\circ} 35^{\prime} 28.66^{\prime \prime} \mathrm{S}, 71^{\circ} 28^{\prime} 26.5^{\prime \prime} \mathrm{W}$ and $189 \mathrm{~m}$ ). The other population came from M. persicae mummies, collected at the beginning of the spring season (September-October) from peach orchards (Duao $35^{\circ} 34^{\prime} 23.23^{\prime \prime} \mathrm{S}$ and $71^{\circ} 33^{\prime} 09.53^{\prime \prime} \mathrm{W}$ $183 \mathrm{~m})$. Parasitoids were determined using taxonomic keys [49,52] and once the population was established, a molecular approach with partial sequences of mtCOI [52,55] was carried out on the progeny to confirm the determination of the species. Parasitoids were fed with $30 \%$ honey solution through soaked cotton wicks and water. Parasitoids were maintained on their respective hosts until the experiments were carried out. New aphids, honey and water were added on a weekly basis to ensure a constant supply of aphids to parasitoids. Rearing and all experiments were maintained under controlled conditions $\left(20 \pm 1{ }^{\circ} \mathrm{C}, 65 \pm 10 \% \mathrm{RH}\right.$ and $16: 8 \mathrm{~h}$ day/night).

\subsubsection{Aphid Hosts}

A polyclonal mass rearing of R. padi on potted wheat Triticum aestivum (Linnaeus) v. Saturnus and M. persicae on mustard Sinapis alba (Linnaeus) were established in the ECOBIO Laboratory in separated Plexiglas cages of $40 \mathrm{~cm}^{3}$. Aphids of both species were used as host resources for parasitoids, as well as in the experiments. Plants and aphids were maintained under summer and controlled laboratory conditions $\left(20 \pm 1{ }^{\circ} \mathrm{C}, 65 \pm 10 \% \mathrm{RH}\right.$ and $16: 8 \mathrm{~h}$ day/night).

\subsubsection{Insect Material for the Experiments}

To standardize parasitoid females used in the experiments, A. platensis mummies were isolated in small plastic tubes $(2 \mathrm{~mL})$ until emergence. Parasitoid emergence was checked once daily at the same time. After emergence, adult parasitoids were sexed and females were left with one to two males for mating over a 24-hour period in micro-cages $(h=20 \mathrm{~cm}, \varnothing=5 \mathrm{~cm})$. They were fed with $30 \%$ honey-water solution using a cotton wick. Virgin females with less than $24 \mathrm{~h}$ old were used in the experiments.

A preliminary experiment was performed to standardize the size of the aphids used in the experiments, therefore, 20 aphids of second and third instars were measured for each of the two-aphid host species (total $n=80$ aphids). The fresh body mass of each individual was measured with a microbalance (XP2U, $\pm 0.0001 \mathrm{mg}$, Mettler Toledo, Columbus, OH, USA). After weighing, each aphid hind tibia length was measured with the numeric image analysis software ImageJ (National Institutes of Health, Bethesda, MD, USA), under a binocular system (SMZ800, Nikon, Tokyo, Japan. with 65× of total magnification) linked to a camera video (JVC KY-F50, JVC Pro, Paris, France). The difference among aphid instars was analyzed by using a Wilcoxon signed rank test. 


\subsection{Host Preference Assay: Choice Experiment}

The host preference of A. platensis was studied by placing one second instar aphid of R. padi and one third instar of M. persicae in a Petri dish arena $(\varnothing=2.5 \mathrm{~cm})$, each on a fresh and non-previously infested leaf of their host plant. The size was chosen because it is in the range used in several choice experiments (between $2-4 \mathrm{~cm}$ ) as in $[51,56]$. Besides, this arena size fitted perfectly to the focus distance and field view of our lens, facilitating the complete observation of the behaviours recorded without moving the arena. Each aphid was placed on a plantlet of $10 \mathrm{~cm}$ high at least $30 \mathrm{~min}$ before the experiments started, in order to allow its establishment on the plant, as in [57]. A piece of the leave with the aphid was cut $5 \mathrm{~min}$ before the experiment and placed in the observation arena. Female parasitoids were introduced into the arena after aphid establishment. The experiment began once the female was released, and ended when the female made a choice (host acceptance), following [58]. During the experiment, the following parasitoid behaviours were used: (i) "first aphid perceived" which can be followed by either rejection (changing direction without contact, before reaching the aphid) or continuation to the next behaviour, (ii) "antennal evaluation", when the parasitoid is moving its antennae just above the aphid or touching the aphid with at least one of its antennae, which is followed by rejection or continuation to the next behaviour, (iii) "abdomen preparation", when the female curved its abdomen in a forward position and could touch the host with its abdomen without any insertion [51,56], (iv) "ovipositor probing" (insertion of the ovipositor not resulting in a successful oviposition); this step can be facultative; (v) "wing fluttering", showing a continuous movement of the wings and (vi) "host acceptance" (ovipositor insertion with abdomen bending and antennae backward, i.e., oviposition). Host handling time for oviposition was considered as the mean time from the encounter (which is followed by antennal evaluation) to a successful oviposition [56]. Additionally, aphids also showed a variety of defensive behaviours in response to the parasitoid's attack that could also lead to rejection from the female [59]. Among aphid defensive behaviours, kicking with the legs, escaping (walking away) and cornicle secretion (at the end of the experiment) were registered. All the behaviours were recorded with the "Etholog" package (v2.2) [60]. After each female choice, both aphid hosts and plant material were replaced, and the experiment was repeated until five different aphids were parasitized by the same female to avoid any hazardous and unpredictable decisions made by the female. The positions of the aphid host species were exchanged at each choice test. A total of 15 females emerging from $R$. padi and 15 from $M$. persicae were used during the experiments. If after $15 \mathrm{~min}$ the female remained inactive, it was replaced by a new female and discarded from the analyses (which happened only once). Within one hour of the experiments, the aphids attacked by females (ovipositor insertion) were dissected to check for parasitoid eggs, in order to ensure that the attack had resulted in a successful oviposition, as in [58].

\subsection{Profitability Assay: Non-choice Experiment}

In order to maximize their fitness, females look for the most profitable host, therefore, we use the term "profitability" as an equivalent of the fitness in the progeny as given in [61]. The aim of this experiment was to measure the performance of parasitoids on both hosts according to their original host. The experiment was carried out on two populations of aphids (R. padi and M. persicae) and two populations of parasitoids (from R. padi and from M. persicae). Micro-cages ( $\mathrm{h}=20 \mathrm{~cm}, \varnothing=5 \mathrm{~cm}$ ) containing $10 \mathrm{~cm}$ high wheat or $10 \mathrm{~cm}$ mustard plantlets with at least two leaves, were infested with $30 \mathrm{~s}$ instar aphids of $R$. padi or 30 third instar aphids of $M$. persicae, respectively. Once the aphids were established on the plants, a female was released into each micro-cage and left to parasitize them for $24 \mathrm{~h}$. After this time, the female was removed and the aphids were monitored until their mummification. Ten replicates per host aphid and per origin of the parasitoid were performed ( $n=40$ females) over two consecutive weeks (five replicates of all the combinations per week). The micro-cages containing the potentially parasitized aphids were checked daily, and once the mummies were formed, they were isolated individually into gelatin capsules $(\varnothing=7 \mathrm{~mm}, 1=1.8 \mathrm{~cm}$; Capsugel Coni-snap 1EL, Morristown, NJ, USA) until parasitoid emergence. Different parameters were evaluated: the parasitism rate was 
calculated by dividing the number of mummies formed by the total number of aphids offered to each female [62]; the emergence rate was calculated as the proportion of parasitoids which emerged from the mummies formed [63]; the developmental time was estimated as the time from oviposition to the emergence of an adult parasitoid, divided between the development time from oviposition (egg) to mummification (larval development) and time from mummification to emergence (nymphal development) as in [58]. Finally, the fresh body mass and tibial lengths of all the emergent individuals were measured. When measuring fresh body mass and tibial lengths, we followed the aforementioned procedure for the aphids. These traits of all emerged progeny were measured during each treatment.

\subsection{Statistical Analysis}

\subsubsection{Choice Experiment}

As each female was tested in five aphid choice tests, generalized estimating equations (i.e., GEE) were used [64] as they allow correlations between repeated measures of a dependent variable to be taken into account [65]. For the analysis, the behavioural parameters were divided into two modalities: The first analysis grouped the First aphid perceived and Host acceptance, which aimed to test whether a female parasitoid from one origin (R. padi or M. persicae) chooses its original host or the alternative, according to the origin of the female (fixed factor). The second analysis grouped the remaining behaviours (e.g., Ovipositor probing, Wing fluttering, etc.), and in addition to the origin of the female evaluated in the first analysis, we considered whether this origin makes the female perform these behaviours differently when facing one or the other host (female origin host and the aphid tested as fixed factors). The interaction between these two explanatory variables on each dependent variable (behaviours) was also considered in all cases. Exchangeable correlation working matrices were used, as no specific patterns for the presentation of the five pairs of aphids was assumed for the GEEs [58]. To select this correlation, we checked previously that the sequence of oviposition choices for each female did not have any influence on the parasitoid behavioural choices. The first aphids perceived and accepted (host acceptance) by the parasitoids were analyzed as the proportion of perceptions/successful ovipositions respectively, with a binomial error and a logit-link function for proportional data [66]. The mean time of wing fluttering and handling time for oviposition were analyzed assuming a Gaussian error and an identity link function. Wing fluttering was analyzed as the mean time the female spent fluttering, considering all the encounters, including those which did not end in a successful oviposition. The presence/absence of cornicular secretions at the end of each assay was analyzed assuming a binomial error and a logit-link function for proportional data [66]. In addition, the number of ovipositor probing (number of stings), aphid kicking (number of aphid kicks) and aphid escaping (number of escapes) were compared using a Poisson error and a log-link function for count data.

\subsubsection{Profitability Assay}

In this assay, we evaluated parasitoid development and fitness proxy variables; the origin of the female and the aphid species chosen were considered as fixed factors, as was the interaction between these two explanatory variables, and we considered the identity of the female as a random factor. The percentage of emergence was compared using a GLMM, assuming a binomial error and a logit-link function. The total developmental time was analyzed with a binomial error and a logit-link function [67]. The parasitism rate was analyzed with a quasibinomial (GLM) error and a logit-link function for proportional data (for overdispersed data). Fresh body mass and the tibial length of the progeny were analyzed using a GLMM, assuming a Gaussian error and an identity link function. In all the cases, models with interactions between the fixed factors were compared using the Akaike information criterion (AIC), and if insignificant, they were not included in the model.

All statistical analyses were performed with the R v.3.5.1 software (R Development Core Team, Vienna, Austria, 2018). For the choice experiment, we used the geepack package for the GEE function. 
For the profitability assay, we used the lme4 package for mixed models [68] and the car package for differences between models with the AIC criterion. To establish significant differences, we used a 'Tukey' test, correcting for multiple comparisons by the 'single-step' method, using the Multcomp package [69].

\section{Results}

\subsection{Preliminary Experiment}

R. padi second instars had a fresh body mass of $0.055 \pm 0.002 \mathrm{mg}$ and a tibia length of $0.336 \pm$ $0.008 \mathrm{~mm}$, whereas third instars had a fresh body mass of $0.124 \pm 0.005 \mathrm{mg}$ and a tibia length of 0519; , $\pm 0010 ; \mathrm{mm}$. In the case of $M$. persicae, second instars had a fresh body mass of $0.049 \pm 0.001 \mathrm{mg}$ and a tibia length of $0.359 \pm 0.006 \mathrm{~mm}$; third instars on the other hand presented a fresh body mass of $0.056 \pm 0.001 \mathrm{mg}$ and a tibia length of $0.407 \pm 0.009 \mathrm{~mm}$. Second and third instars of $R$. padi were heavier than the respective instars of $M$. persicae (second instars: $W=120, p=0.03$; third instars: $W=0$, $p<0.01$ ). However, as the second instars of $R$. padi had a similar fresh body mass to the third instars of M. persicae (Wilcoxon matched paired test, $\mathrm{W}=157, p=0.249$ ), these were finally selected for this study.

\subsection{Choice Experiment}

Female parasitoid first aphid perception was similar in relation to both aphid species regardless of their origin host (Table 1) (Figure 1).

Table 1. Choice experiment. Generalized estimating equations (GEE) showing the effect of the origin host and chosen aphid and the interaction between these two factors on the different behaviours of A. platensis and of the aphids R. Padi and M. persicae. For each level, the degrees of freedom (df), the Chi-square statistical test and the $p$-value are represented.

\begin{tabular}{cccccccccc}
\hline \multirow{2}{*}{ Variables } & \multicolumn{4}{c}{ Origin } & \multicolumn{2}{c}{ Chosen } & \multicolumn{2}{c}{ Interaction } \\
\cline { 2 - 10 } & $\mathbf{d f}$ & $\boldsymbol{X}^{\mathbf{2}}$ & $\boldsymbol{p}$-Value & $\mathbf{d f}$ & $\boldsymbol{X}^{\mathbf{2}}$ & $\boldsymbol{p}$-value & $\mathbf{d f}$ & $\boldsymbol{X}^{\mathbf{2}}$ & $\boldsymbol{p}$-Value \\
\hline First aphid perceived & 1 & 1.08 & 0.30 & - & & & - & & \\
Ovipositor probing & 1 & 0.25 & 0.62 & 1 & 0.65 & 0.42 & 1 & 3.05 & 0.08 \\
Host acceptance & 1 & 14.50 & $1.4 \times 10^{-4}$ & - & & & - & & \\
Handling time for oviposition & 1 & 11.62 & $6.5 \times 10^{-4}$ & 1 & 1.67 & 0.19 & 1 & 0.06 & 0.81 \\
Wing fluttering & 1 & 13.70 & $2.2 \times 10^{-4}$ & 1 & 6.00 & 0.01 & 1 & 0.00 & 0.98 \\
Aphid kicking & 1 & 1.79 & 0.18 & 1 & 10.82 & 0.37 & 1 & 3.82 & 0.05 \\
Aphid escaping & 1 & 2.04 & 0.15 & 1 & 20.97 & $4.7 \times 10^{-6}$ & 1 & 0.61 & 0.44 \\
Cornicular secretions & 1 & 0.00 & 0.97 & 1 & 4.51 & 0.03 & 1 & 0.03 & 0.87 \\
\hline
\end{tabular}

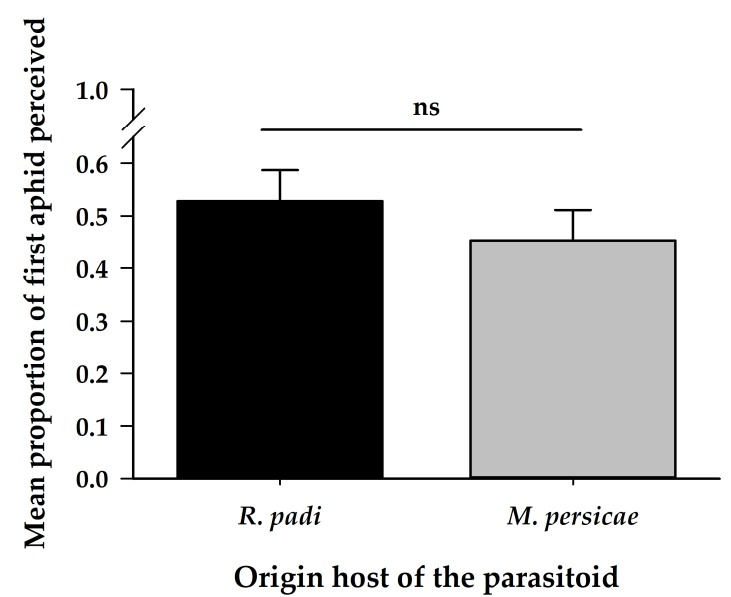

Figure 1. Mean proportion $( \pm \mathrm{SE}$ ) of first aphid perceptions by A. platensis from two origins (R. padi and M. persicae) exposed to these aphid hosts in a paired arena. Asterisks indicate significant differences: 'ns' non-significant $p>0.05$. 
Immediately after antennal contact, parasitoid females spent more time wing fluttering when attacking $R$. padi, than when attacking M. persicae. More time was spent fluttering overall in the case of females of $M$. persicae origin (Table 1) (Figure 2A).

(A)

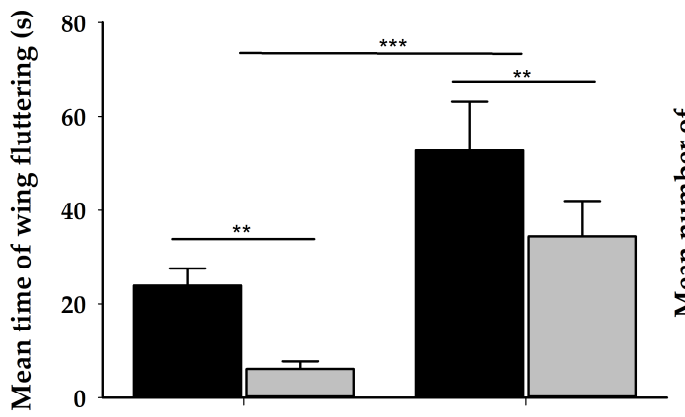

R. padi

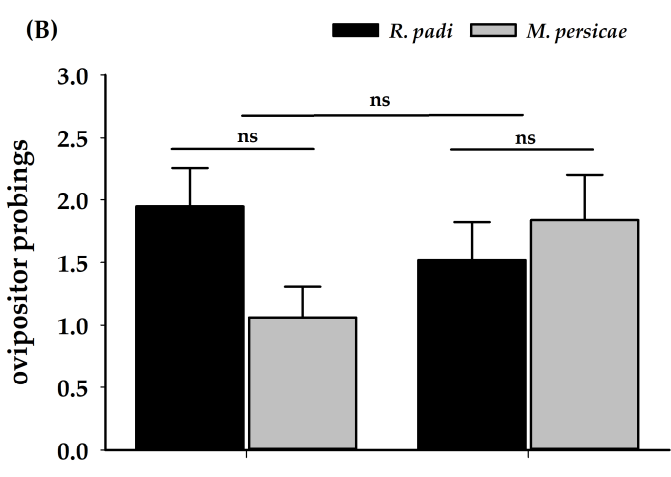

R. padi

M. persicae

Origin host of the parasitoid

Figure 2. (A) Mean time wing fluttering $( \pm S E)$ in seconds, and (B), mean number of ovipositor probings $( \pm \mathrm{SE})$ of A. platensis from two origins (R. padi and M. persicae) exposed to these aphid hosts in a paired arena. Asterisks indicate significant differences: '***' $p<0.001$, '**' $^{* *}<0.01$, 'ns' non-significant $p>0.05$. Black and grey bars show the chosen/tested host.

There was no difference in the number of sting attempts (ovipositor probings) (Table 1) (Figure 2B), females attacked both aphid species, irrespective of their origin host. The proportion of successful ovipositions (host acceptance) was greater on $R$. padi than on M. persicae, regardless of the origin of the female parasitoid (Table 1) (Figure 3). The handling time for oviposition was different, according to the origin of the female parasitoid; females coming from $R$. padi took less time handling a host before an oviposition on both tested hosts was successful, by comparison with females originating from $M$. persicae (Table 1) (Figure 4).

The parasitoid attack of aphids frequently resulted in aphid defensive behaviours; approximately $56 \%$ of $R$. padi and 55\% of $M$. persicae responded to at least one of the three defensive behaviours evaluated. However, M. persicae was more defensive than R. padi when facing the female parasitoid, irrespective of the female origin. Therefore, $R$. padi kicked less than $M$. persicae when attacked by females coming from $M$. persicae (Table 1) (Figure 5A). Likewise, $M$. persicae escaped more times when attacked (Table 1) (Figure 5B). Despite the origin of the female, $R$. padi produced more cornicular secretions when attacked by the females (Figure 5C).

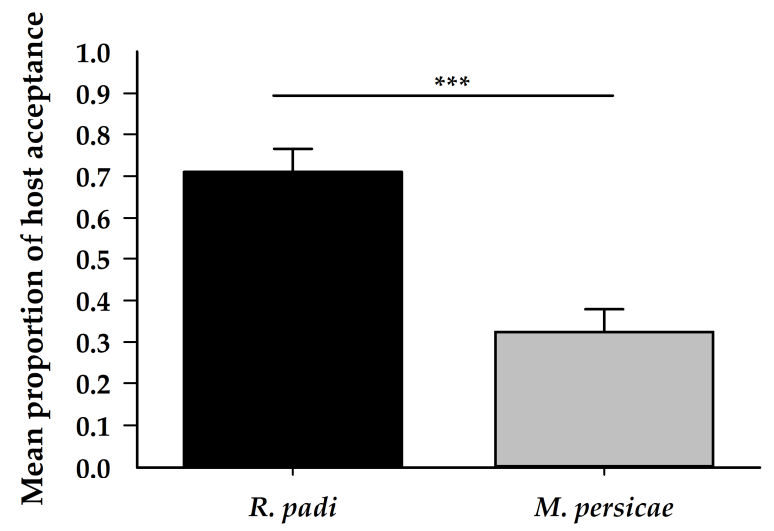

Origin host of the parasitoid

Figure 3. Mean proportion $( \pm \mathrm{SE})$ of chosen aphids according to the origin of A. platensis females. Asterisks indicate significant differences: ${ }^{\prime * * * \prime \prime} p<0.001$. 


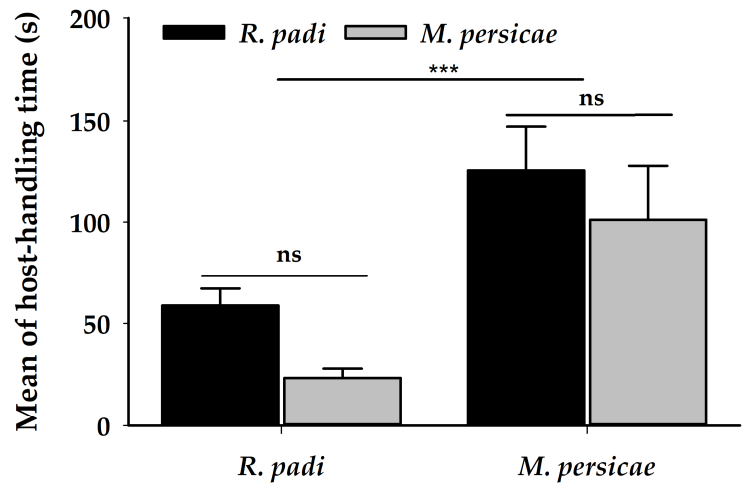

Origin host of the parasitoid

Figure 4. Mean of handling time for oviposition $( \pm \mathrm{SE})$ in seconds of $A$. platensis from two origins (R. padi and M. persicae) exposed to these aphid hosts in a paired arena. Asterisks indicate significant differences: ${ }^{\star * * * \prime} p<0.001$, 'ns' non-significant $p>0.05$. Black and grey bars show the chosen/tested host.
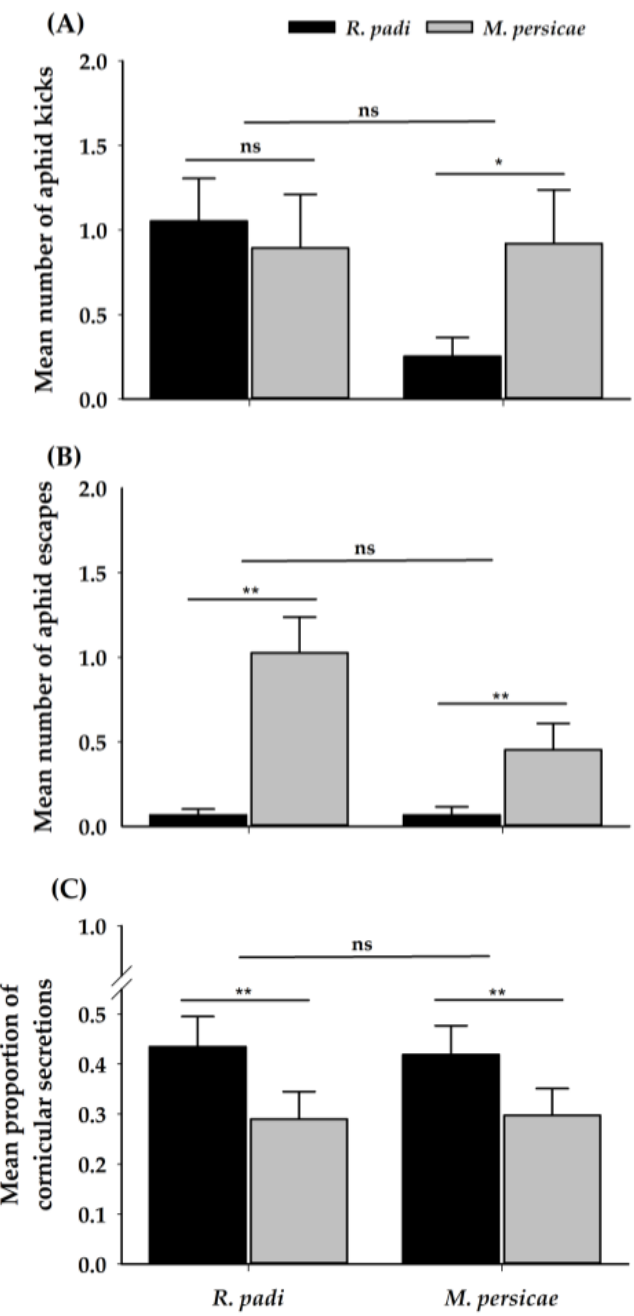

Origin host of the parasitoid

Figure 5. Mean $( \pm \mathrm{SE})$ of aphid defensive behaviours: (A) Number of aphid kicks; (B) Number of aphid escapes and (C) Proportion of an encounter with cornicular secretions of R. padi and M. persicae when attacked by $A$. platensis coming from the two origins. Asterisks indicate significant differences: ‘*’ $p<0.01,{ }^{\prime * \prime} p<0.05$, 'ns' non-significant $p>0.05$. Black and grey bars show the chosen/tested host. 


\subsection{Profitability Assay}

No significant differences were observed for the parasitism rate (Table 2) (Figure 6A). Females of A. platensis parasitized at a similar rate in both aphid species, regardless of their origin host. Otherwise, differences were observed in the proportion of emerged adults, with a greater proportion of progeny of emerged parasitoids when developing on R. padi, irrespective of the origin of the parasitoid mother (Table 2) (Figure 6B). In addition, there were no differences in the total developmental time of the parasitoid progeny (Table 2) (Figure 7) regardless of the origin of the female.

Table 2. Profitability assay. Generalized linear models (GLM) and Generalized linear mixed models (GLMM) showing the effect of the origin host, tested aphid species (M. persicae and R. Padi) and the interaction between these two factors on the profitability traits of $A$. platensis. For each level, the degrees of freedom (df), the Chi square statistical test and the $p$-value are represented.

\begin{tabular}{cccccccccc}
\hline \multirow{2}{*}{ Variables } & \multicolumn{4}{c}{ Origin } & \multicolumn{3}{c}{ Chosen } & \multicolumn{3}{c}{ Interaction } \\
\cline { 2 - 10 } & $\mathbf{d f}$ & $\boldsymbol{X}^{\mathbf{2}}$ & $\boldsymbol{p}$-Value & $\mathbf{d f}$ & $\boldsymbol{X}^{\mathbf{2}}$ & $\boldsymbol{p}$-value & $\mathbf{d f}$ & $\boldsymbol{X}^{\mathbf{2}}$ & $\boldsymbol{p}$-Value \\
\hline Parasitism rate $^{1}$ & 1 & 0.04 & 0.84 & 1 & 2.54 & 0.11 & 1 & 0.00 & 0.95 \\
Emergence $^{2}$ & 1 & 1.01 & 0.32 & 1 & 4.86 & 0.03 & 1 & 0.51 & 0.47 \\
Total developmental time $^{2}$ & 1 & 0.02 & 0.88 & 1 & 0.59 & 0.44 & 1 & 1.13 & 0.29 \\
Tibia length $^{1}$ & 1 & 0.00 & 0.99 & 1 & 1.56 & 0.21 & 1 & 0.04 & 0.84 \\
Fresh body mass $^{1}$ & 1 & 2.18 & 0.14 & 1 & 7.43 & 0.01 & 1 & 0.08 & 0.78 \\
\hline
\end{tabular}

${ }^{1}$ Generalized linear models (GLM), ${ }^{2}$ Generalized linear mixed models (GLMM).
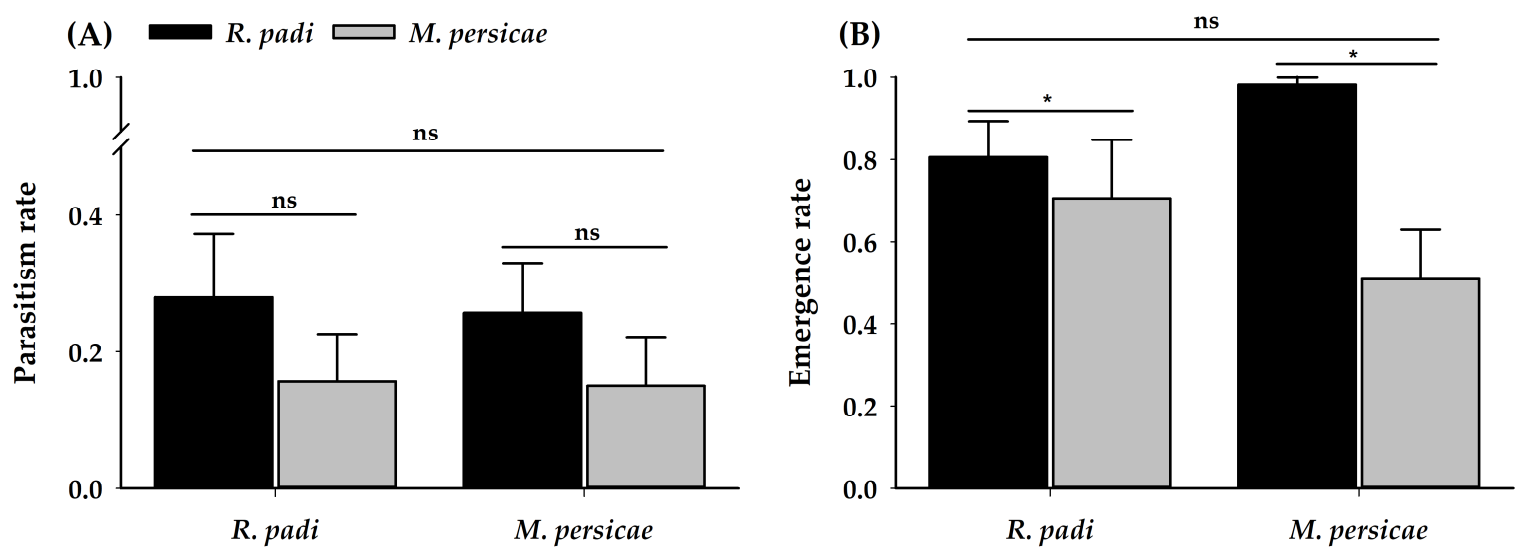

Origin host of the female

Figure 6. (A) Parasitism rate (mean \pm SE) (i.e., proportion of aphid mummies formed) and (B) Emergence rate (mean $\pm \mathrm{SE}$ ) of adult progeny of A. platensis from two origins parasitizing the same aphid host. Asterisks indicate significant differences: ' ${ }^{* \prime} p<0.05$, 'ns' non-significant $p>0.05$. Black and grey bars show the chosen/tested host.

Additionally, fitness traits were evaluated on the emerging progeny in all treatments. There was no difference in the tibia length of the progeny (Table 2) (Figure 8A), irrespective of the origin host of the mother. However, regardless of the origin of the female, the progeny developing on R. padi was heavier than those developing on M. persicae. (Table 2) (Figure 8B). 


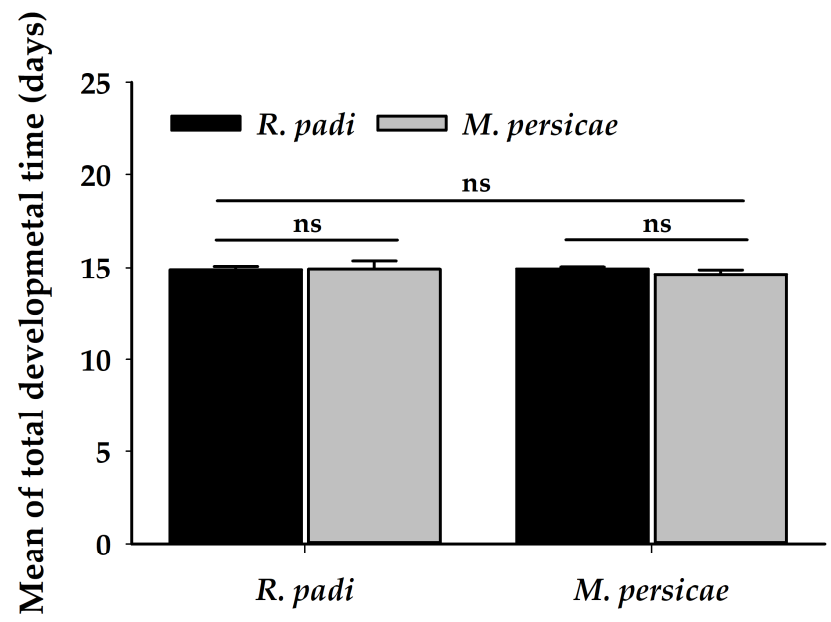

Origin host of the parasitoid

Figure 7. Total developmental time (mean $\pm \mathrm{SE}$ ) of $A$. platensis emerged from $R$. padi and M. persicae and coming from two origins (R. padi and M. persicae). Asterisks indicate significant differences: 'ns' non-significant $p>0.05$. Black and grey bars show the chosen/tested host.
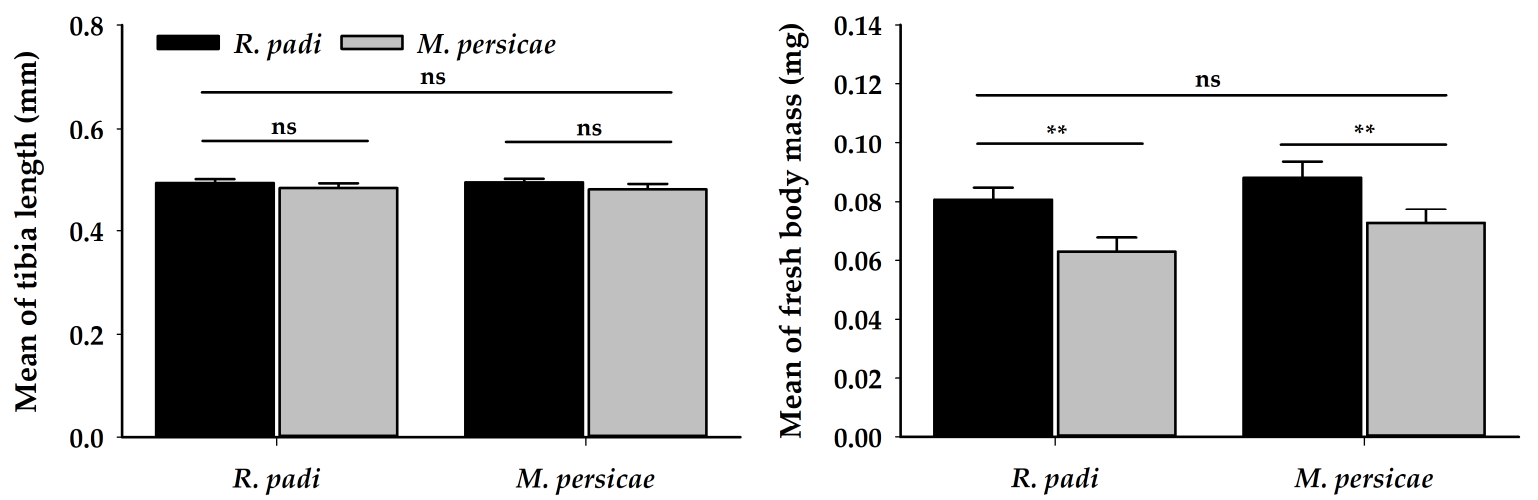

Origin host of the parasitoid

Figure 8. Mean of (A) Tibia length and (B) Fresh body mass $( \pm \mathrm{SE})$ of A. platensis emerged from R. padi and M. persicae and coming from two origins. Asterisks indicate significant differences: ' $* *$ ' $p<0.01$, 'ns' non-significant $p>0.05$. Black and grey bars show the chosen/tested host.

\section{Discussion}

We evaluated the preference and performance of A. platensis individuals, originating from two aphid host populations: R. padi from cereals and M. persicae from P. persica. Our first hypothesis was that parasitoid females will not exhibit host fidelity. Regardless of their origin host, parasitoids preferred $R$. padi, and this seems to be due to the fact that this aphid species was less defensive. Therefore, we do not see an effect of the origin of the female parasitoids (from R. padi or from M. persicae). Our results in non-choice experiments, as expected, confirmed our second hypothesis, as females of both origins were physiologically able to use M. persicae as a host, however, parasitoid progeny emergence was higher and emerging individuals were heavier when developed on R. padi, an important feature in parasitoid fitness [31,70-72]. The implications of this preference for $R$. padi, regardless of the host origin and the suitability of both aphid species for the development of the biological control of M. persicae in the field, are discussed further.

Contrary to host fidelity predictions, A. platensis has a clear preference for R. padi, regardless of the origin host. This lack of host fidelity was found in other studies $[73,74]$ of the A. colemani complex, reared on different aphid hosts, such as Aphis gossypii Glover (Hemiptera: Aphididae) and M. persicae, where an innate preference for A. gossypii was found. Though it is currently unclear 
whether they studied A. colemani per se, as the identity of this species is not clear yet, it is possible that they have also studied A. platensis, as $A$. colemani is now a complex of cryptic, sibling species $[49,75,76]$. It was considered as a group, together with two other close species: A. transcaspicus and A. platensis, probably used as synonyms in several taxonomic descriptions [52,55,77]. Host fidelity is maximized in constant environments, where a continuous supply of aphid hosts is found [37]; e.g., parasitoids from the aphid hosts S. avenae, Acyrthosiphon pisum Harris (Hemiptera: Aphididae) alfalfa race and A. pisum pea race showed a preference for their natal host [51]. However, in their natural habitat, $R$. padi are not available throughout the cereal season, they arrive early in the season and by the end of the season, their populations decrease when S. avenae populations increase [78]. Therefore, a locally adapted A. platensis to R. padi could represent an evolutionary disadvantage. In this context, phenotypic plasticity allows $A$. platensis to adapt to new and/or unpredictable environmental conditions, maximizing their fitness [79-81].

Other reasons that explain the preference for one specific host, could be a better suitability of one host species, or that one aphid species has fewer defensive behaviours, meaning a shorter manipulation time. After an encounter, once a host is recognized through antennal evaluation, as in the case of all parasitoid species, A. platensis females perform different attack behaviours, such as abdomen bending and stings, which could result in a successful oviposition. However, after a host encounter, aphid parasitoids must overcome a variety of aphid defensive behaviours in response to their attacks, which could have an effect on their oviposition behaviour, leading to host rejection [59,72]. In this sense, M. persicae exhibited more defensive behaviours than R. padi (two of the three evaluated). Indeed M. persicae is well known for jerking with its abdomen, as well as walking away (escaping) and kicking [54]. Interestingly, female parasitoids originated from $M$. persicae elicit a lower response to R. padi, which kicked less, when compared to female parasitoids originated from $R$. padi which elicit a greater defensive response in R. padi. Apparently, M. persicae is a more difficult host to deal with, females preferred R. padi (which kick less) over M. persicae, even though they spent a similar amount of time handling the two aphid species. In contrast, R. padi kicked less and spent less time escaping, but the proportion of encounters with cornicular secretions was higher. This latter behaviour is common in R. padi compared to other aphid species [82], as it contains an alarm pheromone ( $\beta$-farnesene), resulting in a deterrent effect on different parts of the parasitoid body [59]. However, in the case of A. platensis, this does not seem to affect its ability to use R. padi as a host. Moreover, as discussed in Ortiz et al. [83], $\beta$-farnesene could be an important cue for host detection in some parasitoids. Further research in the field should aid in the understanding of its role for host recognition and patch exploitation. In addition, $\beta$-farnesene can be used to alert other nearby aphid individuals to prevent damage [59], although this was not evaluated in this study, this should be taken into account for further investigations. In order to cope with aphid defences, parasitoids have evolved different behavioural and physiological mechanisms to efficiently deal with them, from changes in the host exploitation strategies to changes in the host oviposition [84,85]. For instance, according to our results, the handling time ending in a successful oviposition, was shorter in females coming from R. padi, which was the preferred host. In general, shorter handling times increase the reproductive success of a female parasitoid, which has a limited time available to locate suitable hosts, thereby reducing its vulnerability and mortality $[86,87]$. To decrease handling time, parasitoids may avoid hosts that are potentially difficult to handle, which is an adaptive behaviour [88]. The latter could help us understand why females of $A$. platensis avoided handling M. persicae (which showed more defensive behaviours) over R. padi (easier to handle). However, this could be related to the time spent wing fluttering. It was observed that different species of Aphidiinae spend different lengths of time wing fluttering (higher or lesser) when attacking a host, and it was shown, that when it occurs, less aphid defensive behaviours are produced, especially cornicular secretions [56]. Our results showed that females originating from $R$. padi spent less time fluttering their wings, however, irrespective of origin, females spent more time wing fluttering on R. padi than on M. persicae. Likewise, regardless of origin, the proportion of encounters with cornicular secretions was higher on R. padi than on M. persicae. Therefore, a different 
pattern among wing fluttering and cornicular secretion in R. padi was found in this study. However, although $R$. padi produced higher cornicular secretions, they were still preferred by A. platensis females.

As $A$. platensis populations were collected and reared on both hosts, they were expected to survive and develop on both aphid hosts. Here, in non-choice situations, A. platensis females were able to oviposit on M. persicae with no difference in the parasitism rates and the development time, however, in our study, regardless of the origin of the female, the progeny was always heavier when developing on R. padi (Figure 8B). This was irrespective of whether we offered aphids of the same initial size to females of A. platensis in order to provide the same amount of resources (second instar of R. padi and third instar of M. persicae). As host size is an important feature in parasitoid fitness $[31,70,71]$ it has a positive relationship with the fitness of parasitoid progeny, as larger hosts usually contain more resources than smaller hosts $[29,30,40,72,89,90]$.Thus, host size determines the host quality in which the progeny will develop [70]. Additionally, as proposed by Sequeira and Mackauer [91], a suitable host should be susceptible to parasitism and provide at least the minimum nutritional and physiological requirements for parasitoid development. Therefore, nutritional levels are important features (i.e., amino acid and lipid content) in the aphid hosts, which would explain their better physiological suitability. Due to the nutritional value of aphids (i.e., fatty acids and calories), these contents could have consequences at the third trophic level [92], mainly for parasitoid larvae development and later in reproduction $[92,93]$.

In general, low parasitism was observed on both aphid hosts under laboratory conditions (Figure 6A), however, the emergence rate was higher on $R$. padi from females of both origins. These results suggest that $R$. padi would be a slightly more profitable host, however, M. persicae is also suitable. This is in contrast with the results of, Ode et al. [87] that measured the suitability of four aphid species for the closely related species parasitoid A. colemani: A. gossypii, M. persicae, R. padi, and Schizaphis graminum (Rondani) (Hemiptera: Aphididae). They showed that R. padi is a less suitable and a poor-quality host, compared to the other three Israelian aphid species tested, yet it appears to be a more favourable host, due to the larger size of parasitoids developing in it. Therefore, a trade-off between larval survival and body size among $R$. padi and A. gossypii is observed. The higher profitability of R. padi can explain that this species is the preferred host by A. platensis. However, our study also shows that $M$. persicae can easily be acceptable as there is no host fidelity, especially if R. padi populations are not present or are a scarce resource.

Given the results of preference and development obtained in this laboratory study, it could help explain the biological control of orchard pest results in the field when using cereal cover crops for alternative hosts such as R. padi. Therefore, we could expect that at the beginning of the season (in winter), A. platensis would attack R. padi in cereals (alternative host) as M. persicae is not present in orchards. Therefore, when the first populations of M. persicae on Prunus trees would appear and start damaging trees (early spring), there would be a short overlap of both crops (cereals and Prunus trees). However, in early spring, populations of $R$. padi would leave the cereals and move to other gramineous habitats, as they cannot colonize Prunus domestica (Linnaeus) and P. persica. Hence, as both hosts are suitable for the development of A. platensis (performance assay), when R. padi populations are no longer available, we can expect that the parasitoids could change hosts to M. persicae in Prunus, controlling their populations and improving biological control. However, since host selection of the most profitable aphid host by a female parasitoid includes a variety of other interacting factors as chemical and visual cues on field, further studies on host finding, searching behaviour are important for understanding the mechanisms involved in this more complex system.

\section{Conclusions}

From our results, we were able to obtain some evidence of the host foraging behaviour of A. platensis females, when faced with two different aphid species, as well as information regarding the interactions between them. This could have implications for conservation biological control, by ensuring that the alternative hosts used, provided the expected positive effects on beneficial organisms to control pests. 
By performing thorough laboratory experiments, we could obtain a first approach with the aim of establishing more efficient pest management strategies in orchard systems.

Author Contributions: Conceptualization, J.K.A.-B., J.V.B., C.L.L. and B.L.; methodology, J.K.A.-B., A.A.-T., J.V.B., C.L.L. and B.L.; software, J.K.A.-B., A.A.-T., J.V.B., C.L.L. and B.L.; validation, J.K.A.-B., A.A.-T., J.V.B., C.L.L. and B.L.; formal analysis, J.K.A.-B., C.L.L. and B.L.; resources, J.K.A.-B., J.V.B., C.L.L. and B.L.; data curation, J.K.A.-B.; writing-review and editing, J.K.A.-B., A.A.-T., J.V.B., C.L.L. and B.L.; project administration, B.L., J.V.B., C.L.L. and J.K.A.-B.; funding acquisition, B.L., J.V.B., C.L.L. and J.K.A.-B. All authors have read and agreed to the published version of the manuscript.

Funding: This study was funded by Fondo Nacional de Desarrollo Científico y Tecnológico (FONDECYT) Regular Grant $N^{\circ} 1180601$ to B.L. J.K.A.-B. was funded by the ANID-PFCHA/BECAS DE DOCTORADO NACIONAL/2018-21181816 and AAT received a doctoral grant from the Talca University (Chile). Travel grants were funded by project Marie Currie APHIDWEB, 10254/2014.). B.L. and J.K.A.-B. would like to thank ANID/PIA/ACT192027 for funding provided during the writing of this manuscript.

Acknowledgments: The authors would like to thank Cinthya Villegas and Nuri Cabrera for their assistance in the field work, as well as Stephanie Llopis and Emma Jeavons for their help in parasitoid measurement. Thanks also to The ECOLEX platform and Thierry Fontaine for providing the plant material.

Conflicts of Interest: The authors declare no conflict of interest. The funders had no role in the design of the study, in the collection, analyses or interpretation of data, in the writing of the manuscript or in the decision to publish the results.

\section{References}

1. Cardinale, B.J.; Srivastava, D.S.; Duffy, J.E.; Wright, J.P.; Downing, A.L.; Sankaran, M.; Jouseau, C.; Cadotte, M.W.; Carroll, I.T.; Weis, J.J.; et al. Effects of biodiversity on the functioning of ecosystems: A summary of 164 experimental manipulations of species richness. Ecology 2009, 90, 854. [CrossRef]

2. Pickett, C.H.; Roltsch, W.; Corbett, A. The role of rubidium marked natural enemy refuge in the establishment and movement of Bemisia parasitoids. Int. J. Pest Manag. 2004, 50, 183-191. [CrossRef]

3. Quijas, S.; Schmid, B.; Balvanera, P. Plant diversity enhances provision of ecosystem services: A new synthesis. Basic Appl. Ecol. 2010, 11, 582-593. [CrossRef]

4. Fiedler, A.K.; Landis, D.A. Attractiveness of michigan native plants to arthropod natural enemies and herbivores. Environ. Entomol. 2015, 36, 751-765. [CrossRef]

5. Gurr, G.; Wratten, S. Biological Control: Measures of Success, 1st ed.; Gurr, G., Wratten, S., Eds.; Kluwer Academic Publishers: Dordrecht, The Netherlands, 2000; ISBN 978-1-4020-1052-1.

6. Landis, D.A.; Wratten, S.D.; Gurr, G.M. Habitat management to conserve natural enemies of arthropod pests in agriculture. Annu. Rev. Entomol. 2000, 45, 175-201. [CrossRef]

7. Holland, J.M.; Bianchi, F.J.; Entling, M.H.; Moonen, A.C.; Smith, B.M.; Jeanneret, P. Structure, function and management of semi-natural habitats for conservation biological control: A review of European studies. Pest Manag. Sci. 2016, 72, 1638-1651. [CrossRef]

8. Begg, G.S.; Cook, S.M.; Dye, R.; Ferrante, M.; Franck, P.; Lavigne, C.; Lövei, G.L.; Mansion-Vaquie, A.; Pell, J.K.; Petit, S.; et al. A functional overview of conservation biological control. Crop. Prot. 2017, 97, 145-158. [CrossRef]

9. Fiedler, A.K.; Landis, D.A.; Wratten, S.D. Maximizing ecosystem services from conservation biological control: The role of habitat management. Biol. Control 2008, 45, 254-271. [CrossRef]

10. Naranjo, S.E.; Ellsworth, P.C. Fifty years of the integrated control concept: Moving the model and implementation forward in Arizona. Pest Manag. Sci. 2009, 65, 1267-1286. [CrossRef]

11. Bottrell, D.G.; Schoenly, K.G. Resurrecting the ghost of green revolutions past: The brown planthopper as a recurring threat to high-yielding rice production in tropical Asia. J. Asia Pac. Entomol. 2012, 15, 122-140. [CrossRef]

12. Byrne, M.L.; Christie, M.E.; Luke, T.W. Insect pest management in Tropical asian irrigated rice. Annu. Rev. Entomol. 2011, 45, 549-574.

13. Wyckhuys, K.A.G.; Lu, Y.; Morales, H.; Vazquez, L.L.; Legaspi, J.C.; Eliopoulos, P.A.; Hernandez, L.M. Current status and potential of conservation biological control for agriculture in the developing world. Biol. Control 2013, 65, 152-167. [CrossRef] 
14. Onzo, A.; Hanna, R.; Negloh, K.; Toko, M.; Sabelis, M.W. Biological control of cassava green mite with exotic and indigenous phytoseiid predators-Effects of intraguild predation and supplementary food. Biol. Control 2005, 33, 143-152. [CrossRef]

15. Pretty, J.; Bharucha, Z.P. Integrated pest management for sustainable intensification of agriculture in Asia and Africa. Insects 2015, 6, 152-182. [CrossRef] [PubMed]

16. Peñalver-Cruz, A.; Alvarez-Baca, J.K.; Alfaro-Tapia, A.; Gontijo, L.; Lavandero, B. Manipulation of agricultural habitats to improve conservation biological control in South America. Neotrop. Entomol. 2019, 48, 875-898. [CrossRef]

17. Irvin, N.A.; Bistline-East, A.; Hoddle, M.S. The effect of an irrigated buckwheat cover crop on grape vine productivity, and beneficial insect and grape pest abundance in southern California. Biol. Control 2016, 93, 72-83. [CrossRef]

18. Landis, D.A. Designing agricultural landscapes for biodiversity-based ecosystem services. Basic Appl. Ecol. 2017, 18, 1-12. [CrossRef]

19. Welch, K.D.; Harwood, J.D. Temporal dynamics of natural enemy-pest interactions in a changing environment. Biol. Control 2014, 75, 18-27. [CrossRef]

20. Rusch, A.; Bommarco, R.; Ekbom, B. Conservation biological control in agricultural landscapes. Adv. Bot. Res. 2016, 81, 1-28.

21. Lundgren, J.G.; Wyckhuys, K.A.G.; Desneux, N. Population responses by Orius insidiosus to vegetational diversity. BioControl 2009, 54, 135-142. [CrossRef]

22. Gómez-Marco, F.; Urbaneja, A.; Tena, A. A sown grass cover enriched with wild forb plants improves the biological control of aphids in citrus. Basic Appl. Ecol. 2016, 17, 210-219. [CrossRef]

23. Irvin, N.A.; Scarratt, S.L.; Wratten, S.D.; Frampton, C.M.; Chapman, R.B.; Tylianakis, J.M. The effects of floral understoreys on parasitism of leafrollers (Lepidoptera: Tortricidae) on apples in New Zealand. Agric. Entomol. 2006, 8, 25-34. [CrossRef]

24. Frank, S.D. Biological control of arthropod pests using banker plant systems: Past progress and future directions. Biol. Control 2010, 52, 8-16. [CrossRef]

25. MacArthur, R.; Pianka, E. On optimal use of a patchy environment. Am. Nat. 1966, 100, 603-609. [CrossRef]

26. Jaenike, J. On optimal oviposition behavior in phytophagous insects. Theor. Popul. Biol. 1978, 14, 350-356. [CrossRef]

27. Chesnais, Q.; Ameline, A.; Doury, G.; Le Roux, V.; Couty, A. Aphid parasitoid mothers don't always know best through the whole host selection process. PLoS ONE 2015, 10, 1-16. [CrossRef]

28. Gripenberg, S.; Mayhew, P.J.; Parnell, M.; Roslin, T. A meta-analysis of preference-performance relationships in phytophagous insects. Ecol. Lett. 2010, 13, 383-393. [CrossRef]

29. Henry, L.M.; Gillespie, D.R.; Roitberg, B.D. Does mother really know best? Oviposition preference reduces reproductive performance in the generalist parasitoid Aphidius ervi. Entomol. Exp. Appl. 2005, 116, 167-174. [CrossRef]

30. Chau, A.; Mackauer, M. Preference of the aphid parasitoid Monoctonus paulensis (Hymenoptera: Braconidae, Aphidiinae) for different aphid species: Female choice and offspring survival. Biol. Control 2001, 20, 30-38. [CrossRef]

31. Mackauer, M.; Michaud, J.P.; Völkl, W. Host choice by aphidiid parasitoids (Hymenoptera: Aphidiidae): Host recognition, host quality, and host value. Can. Entomol. 1996, 128, 959-980. [CrossRef]

32. Eoche-Bosy, D.; Outreman, Y.; Oliveira Andrade, T.; Krespi, L.; van Baaren, J. Seasonal variations of host resources influence foraging strategy in parasitoids. Entomol. Exp. Appl. 2016, 161, 11-19. [CrossRef]

33. Godfray, H.C.J. Parasitoids: Behavioral and Evolutionary Ecology; Princeton University Press: Princeton, NJ, USA, 1994; ISBN 9780691000473.

34. Straub, C.S.; Ives, A.R.; Gratton, C. Evidence for a trade-off between host-range breadth and host-use efficiency in aphid parasitoids. Am. Nat. 2011, 177, 389-395. [CrossRef] [PubMed]

35. Drès, M.; Mallet, J. Host races in plant-feeding insects and their importance in sympatric speciation. Philos. Trans. R. Soc. B Biol. Sci. 2002, 357, 471-492. [CrossRef] [PubMed]

36. Medina, R.F. Differentiation in the Control of Pest Species. In Insect Outbreak Revisited; Barbosa, P., Letourneau, D., Agrawal, A., Eds.; Blackwell Publishing LTD: Hoboken, NJ, USA, 2012; pp. 291-310.

37. Forbes, A.A.; Powell, T.H.Q.; Stelinski, L.L.; Smith, J.J.; Feder, J.L. Sequential sympatric speciation across trophic levels. Science 2009, 323, 776-779. [CrossRef] [PubMed] 
38. Davis, J.M.; Stamps, J.A. The effect of natal experience on habitat preferences. Trends Ecol. Evol. 2004, 19, 411-416. [CrossRef]

39. Henry, L.M.; Roitberg, B.D.; Gillespie, D.R. Host-range evolution in Aphidius parasitoids: Fidelity, virulence and fitness trade-offs on an ancestral host. Evolution 2008, 62, 689-699. [CrossRef] [PubMed]

40. Henry, L.M.; Ma, B.O.; Roitberg, B.D. Size-mediated adaptive foraging: A host-selection strategy for insect parasitoids. Oecologia 2009, 161, 433-445. [CrossRef]

41. Fuentes-Contreras, E.; Muñoz, R.; Niemeyer, H.M. Diversity of aphids (Hemiptera Aphidoidea) in Chile. Rev. Chil. Hist. Nat. 1997, 70, 531-542.

42. Nieto Nafría, J.M.; Fuentes-Contreras, E.; Castro Colmenero, M.; Aldea Piera, M.; Ortego, J.; Mier Durante, M.P.; Durante, M.P.M. Catálogo de los áfidos (Hemiptera, Aphididae) de Chile, con plantas hospedadoras y distribuciones regional y provincial. Graellsia 2016, 72, 50. [CrossRef]

43. Bass, C.; Puinean, A.M.; Zimmer, C.T.; Denholm, I.; Field, L.M.; Foster, S.P.; Gutbrod, O.; Nauen, R.; Slater, R.; Williamson, M.S. The evolution of insecticide resistance in the peach potato aphid, Myzus persicae. Insect Biochem. Mol. Biol. 2014, 51, 41-51. [CrossRef]

44. Fuentes-Contreras, E.; Figueroa, C.; Reyes, M.; Briones, L.; Niemeyer, H. Genetic diversity and insecticide resistance of Myzus persicae (Hemiptera:Aphididae) populations from tobacco in Chile: Evidence for the existence of a single predominant clone. Bull. Entomol. Res. 2004, 94, 11-18. [CrossRef] [PubMed]

45. Lavandero, B.; Miranda, M.; Ramirez, C.C.; Fuentes-Contreras, E. Landscape composition modulates population genetic structure of Eriosoma lanigerum (Hausmann) on Malus domestica Borkh in central Chile. Bull. Entomol. Res. 2009, 99, 97-105. [CrossRef] [PubMed]

46. Llewellyn, K.S.; Loxdale, H.D.; Harrington, R.; Brookes, C.P.; Clark, S.J.; Sunnucks, P. Migration and genetic structure of the grain aphid (Sitobion avenae) in Britain related to climate and clonal fluctuation as revealed using microsatellites. Mol. Ecol. 2003, 12, 21-34. [CrossRef] [PubMed]

47. Blackman, R.; Eastop, V. Aphids on the World's Crops: An Identification and Information Guide, 2nd ed.; John Wiley \& Sons: Chichester, UK, 2000; ISBN 9780471851912.

48. Ffrench-Constant, R.H. The molecular genetics of insecticide resistance. Genetics 2013, 194, 807-815. [CrossRef]

49. Starý, P. The Aphidiidae of Chile. Dtsch. Èntomol. Z. 1995, 42, 113-138.

50. Starý, P. Aphidius platensis Brethes, its distribution and host range (Hym.: Aphidiidae). Orient. Insects 1972, 6, 359-370. [CrossRef]

51. Zepeda-Paulo, F.A.; Ortiz-Martínez, S.A.; Figueroa, C.C.; Lavandero, B. Adaptive evolution of a generalist parasitoid: Implications for the effectiveness of biological control agents. Evol. Appl. 2013, 6, 983-999. [CrossRef]

52. Tomanovic, Ž.; Petrovic, A.; Mitrovic, M.; Kavallieratos, N.; Stary, P.; Rakhshani, E.; Rashanipour, M.; Popovic, A.; Shukshuk, A.; Ivanovic, A. Molecular and morphological variability within the Aphidius colemani group with redescription of Aphidius platensis Brethes (Hymenoptera: Braconidae: Aphidiinae). Bull. Entomol. Res. 2014, 104, 552-565. [CrossRef]

53. Starý, P. Biology of Aphids Parasites (Hymenoptera: Aphidiidae) with Respect to Integrated Control; Springer: The Hague, The Netherlands, 1970; ISBN 978-90-6193-116-4.

54. Rakhshani, E.; Barahoei, H.; Ahmad, Z.; Starý, P.; Ghafouri-Moghaddam, M.; Mehrparvar, M.; Kavallieratos, N.G.; Čkrkić, J.; Tomanović, Ž. Review of aphidiinae parasitoids (hymenoptera: Braconidae) of the middle east and north Africa: Key to species and host associations. Eur. J. Taxon. 2019, 2019, 1-132. [CrossRef]

55. Hwang, H.S.; Jung, D.O.; Kim, J.W.; Lee, K.Y. Molecular identification of Aphidius transcaspicus (Hymenoptera: Braconidae: Aphidiinae), a closely associated species of Aphidius colemani, in Korea. J. Asia Pac. Entomol. 2018, 21, 1246-1252. [CrossRef]

56. Van Baaren, J.; Héterier, V.; Hance, T.; Krespi, L.; Cortesero, A.M.; Poinsot, D.; Le Ralec, A.; Outreman, Y. Playing the hare or the tortoise in parasitoids: Could different oviposition strategies have an influence in host partitioning in two Aphidius species? Ethol. Ecol. Evol. 2004, 16, 231-242. [CrossRef]

57. Le Lann, C.; Outreman, Y.; Van Alphen, J.J.M.; Krespi, L.; Pierre, J.S.; Van Baaren, J. Do past experience and competitive ability influence foraging strategies of parasitoids under interspecific competition? Ecol. Entomol. 2008, 33, 691-700. [CrossRef] 
58. Le Lann, C.; Wardziak, T.; van Baaren, J.; van Alphen, J.J.M. Thermal plasticity of metabolic rates linked to life-history traits and foraging behaviour in a parasitic wasp. Funct. Ecol. 2011, 25, 641-651. [CrossRef]

59. Le Ralec, A.; Anselme, C.; Outreman, Y.; Poirié, M.; Van Baaren, J.; Le Lann, C.C.; Van Alphen, J.J.M. Evolutionary ecology of the interactions between aphids and their parasitoids. C. R. Biol. 2010, 333, 554-565. [CrossRef] [PubMed]

60. Ottoni, E.B. EthoLog 2.2: A tool for the transcription and timing of behavior observation sessions. Behav. Res. Methods Instrum. Comput. 2000, 32, 446-449. [CrossRef] [PubMed]

61. Henry, L.M.; Roitberg, B.D. Parasitoids. In Encyclopedia of Animal Behavior; Breed, M.D., Moore, J., Eds.; Academic Press: Cambridge, MA, USA, 2010; pp. 651-656. ISBN 978-0-08-045337-8.

62. Antolin, M.F.; Bjorksten, T.A.; Vaughn, T.T. Host-related fitness trade-offs in a presumed generalist parasitoid, Diaeretiella rapae (Hymenoptera: Aphidiidae). Ecol. Entomol. 2006, 31, 242-254. [CrossRef]

63. Henry, L.M.; May, N.; Acheampong, S.; Gillespie, D.R.; Roitberg, B.D. Host-adapted parasitoids in biological control: Does source matter? Ecol. Appl. 2010, 20, 242-250. [CrossRef]

64. Liang, K.; Zeger, S. Longitudinal data analysis using generalized linear models. Biometrika 1986, 73, 13-22. [CrossRef]

65. Hardin, J.W.; Hilbe, J.M. Generalized Estimating Equations, 2nd ed.; Chapman \& Hall/CRC: New York, NY, USA, 2012; ISBN 978-1-4398-8113-2.

66. McCullagh, P.; Nelder, J. Generalized Linear Models, 2nd ed.; Chapman \& Hall/CRC: New York, NY, USA, 1989; ISBN 9780412317606.

67. Harrison, X.A.; Donaldson, L.; Correa-Cano, M.E.; Evans, J.; Fisher, D.N.; Goodwin, C.E.D.; Robinson, B.S.; Hodgson, D.J.; Inger, R. A brief introduction to mixed effects modelling and multi-model inference in ecology. PeerJ 2018, 2018, 1-32. [CrossRef]

68. Bates, D.; Mächler, M.; Bolker, B.; Walker, S. Fitting linear mixed-effects models using lme4. J. Stat. Softw. 2015, 67, 1-48. [CrossRef]

69. Hothorn, T.; Bretz, F.; Westfall, P. Simultaneous inference in general parametric models. Biom. J. 2008, 50, 346-363. [CrossRef] [PubMed]

70. He, X.Z.; Wang, Q.; Teulon, D.A.J. Host age preference behavior in Aphidius ervi Haliday (Hymenoptera: Aphidiidae). J. Insect Behav. 2011, 24, 447-455. [CrossRef]

71. Cloutier, C.; Duperron, J.; Tertuliano, M.; McNeil, J.N. Host instar, body size and fitness in the koinobiotic parasitoid Aphidius nigripes. Entomol. Exp. Appl. 2000, 97, 29-40. [CrossRef]

72. Wyckhuys, K.A.G.; Stone, L.; Desneux, N.; Hoelmer, K.A.; Hopper, K.R.; Heimpel, G.E. Parasitism of the soybean aphid, Aphis glycines by Binodoxys communis: The role of aphid defensive behaviour and parasitoid reproductive performance. Bull. Entomol. Res. 2008, 98, 361-370. [CrossRef] [PubMed]

73. Messing, R.H.; Rabasse, J.M. Oviposition behaviour of the polyphagous aphid parasitoid Aphidius colemani Viereck (Hymenoptera: Aphidiidae). Agric. Ecosyst. Environ. 1995, 52, 13-17. [CrossRef]

74. Perdikis, D.C.; Lykouressis, D.P.; Garantonakis, N.G.; Iatrou, S.A. Instar preference and parasitization of Aphis gossypii and Myzus persicae (Hemiptera: Aphididae) by the parasitoid Aphidius colemani (Hymenoptera: Aphidiidae). Eur. J. Entomol. 2004, 101, 333-336. [CrossRef]

75. Starý, P. The fate of released parasitoids (Hymenoptera, Braconidae, Aphidiinae) for biological-control in Chile. Bull. Entomol. Res. 1993, 83, 633-639. [CrossRef]

76. Starý, P. Aphidius colemani Viereck: Its taxonomy, distribution and host range (Hymenoptera, Aphidiidae). Acta Entomol. Bohemoslov. 1975, 72, 156-173.

77. Santos, C.; Sampaio, M.; Lau, D.; Redaelli, L.; Jahnke, S.; Pivato, J.; Carvalho, F. Taxonomic status and population oscillations of Aphidius colemani species group (Hymenoptera: Braconidae) in Southern Brazil. Neotrop. Entomol. 2019, 48, 983-991. [CrossRef]

78. Gianoli, E. Competition in cereal aphids (Homoptera: Aphididae) on wheat plants. Environ. Entomol. 2000, 29, 213-219. [CrossRef]

79. Crispo, E. Modifying effects of phenotypic plasticity on interactions among natural selection, adaptation and gene flow. J. Evol. Biol. 2008, 21, 1460-1469. [CrossRef] [PubMed]

80. Martel, V.; Darrouzet, E.; Boivin, G. Phenotypic plasticity in the reproductive traits of a parasitoid. J. Insect Physiol. 2011, 57, 682-687. [CrossRef] [PubMed]

81. Thibert-Plante, X.; Hendry, A.P. The consequences of phenotypic plasticity for ecological speciation. J. Evol. Biol. 2011, 24, 326-342. [CrossRef] [PubMed] 
82. Calvert, D.J. Experimental host preferences of Monoctonus paulensis (Hymenoptera: Braconidae), including a hypothetical scheme of host selection. Ann. Entomol. Soc. Am. 1973, 66, 28-33. [CrossRef]

83. Ortiz-Martínez, S.; Pierre, J.S.; van Baaren, J.; Le Lann, C.; Zepeda-Paulo, F.; Lavandero, B. Interspecific competition among aphid parasitoids: Molecular approaches reveal preferential exploitation of parasitized hosts. Sci. Rep. 2019, 9, 1-11. [CrossRef] [PubMed]

84. Desneux, N.; Barta, R.J.; Hoelmer, K.A.; Hopper, K.R.; Heimpel, G.E. Multifaceted determinants of host specificity in an aphid parasitoid. Oecologia 2009, 160, 387-398. [CrossRef] [PubMed]

85. De Farias, A.M.I.; Hopper, K.R. Oviposition behavior of Aphelinus asychis (Hymenoptera. Aphelinidae) and Aphidius matricariae (Hymenoptera: Aphidiidae) and defense behavior of their host Diuraphis noxia (Homoptera: Aphididae). Environ. Entomol. 1999, 28, 858-862. [CrossRef]

86. Heimpel, G.E.; Rosenheim, J.A.; Mangel, M. Predation on adult Aphytis parasitoids in the field. Oecologia 1997, 110, 346-352. [CrossRef]

87. Ode, P.J.; Hopper, K.R.; Coll, M. Oviposition vs. offspring fitness in Aphidius colemani parasitizing different aphid species. Entomol. Exp. Appl. 2005, 115, 303-310. [CrossRef]

88. Kouamé, K.L.; Mackauer, M. Influence of aphid size, age and behaviour on host choice by the parasitoid wasp Ephedrus californicus: A test of host-size models. Oecologia 1991, 88, 197-203. [CrossRef]

89. Cohen, J.E.; Jonsson, T.; Müller, C.B.; Godfray, H.C.J.; Van Savage, M. Body sizes of hosts and parasitoids in individual feeding relationships. Proc. Natl. Acad. Sci. USA 2005, 102, 684-689. [CrossRef] [PubMed]

90. Shu-sheng, L. Development, adult size and fecundity of Aphidius sonchi reared in two instars of its aphid host, Hyperomyzus lactucae. Entomol. Exp. Appl. 1985, 37, 41-48. [CrossRef]

91. Sequeira, R.; Mackauer, M. The nutritional ecology of a parasitoid wasp, Ephedrus californicus Baker (Hymenoptera: Aphidiidae). Can. Entomol. 1993, 125, 423-430. [CrossRef]

92. Giles, K.L.; Madden, R.D.; Stockland, R.; Payton, M.E.; Dillwith, J.W. Host plants affect predator fitness via the nutritional value of herbivore prey: Investigation of a plant-aphid-ladybeetle system. BioControl 2002, 47, 1-21. [CrossRef]

93. Douglas, A.E. The Nutritional Physiology of Aphids; Academic Press: Cambridge, MA, USA, 2003; Volume 31, ISBN 0120242311.

(C) 2020 by the authors. Licensee MDPI, Basel, Switzerland. This article is an open access article distributed under the terms and conditions of the Creative Commons Attribution (CC BY) license (http://creativecommons.org/licenses/by/4.0/). 